\title{
CORRECTION
}

\section{Novel genotype-phenotype and MRI correlations in a large cohort of patients with SPG7 mutations}

Neurol Genet 2018;4:e300. doi:10.1212/NXG.0000000000000300

In the article, "Novel genotype-phenotype and MRI correlations in a large cohort of patients with SPG7 mutations" by Hewamadduma, et al. ${ }^{1}$, first published online on October 24, 2018, the email address for the corresponding author should read as c.hewamadduma@nhs.net. The authors regret the error.

\section{Reference}

Hewamadduma CA, Hoggard N, O'Malley R, et al. Novel genotype-phenotype and MRI correlations in a large cohort of patients with SPG7 mutations. Neurol Genet 2018;4:e279. 


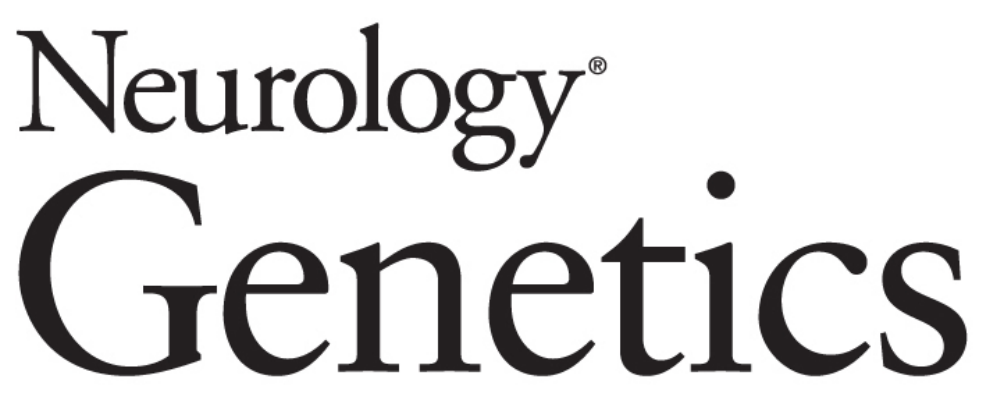

Novel genotype-phenotype and MRI correlations in a large cohort of patients with SPG7 mutations

Neurol Genet 2018;4;

DOI 10.1212/NXG.0000000000000300

This information is current as of December 3, 2018

$\begin{array}{ll}\begin{array}{l}\text { Updated Information \& } \\ \text { Services }\end{array} & \begin{array}{l}\text { including high resolution figures, can be found at: } \\ \text { http://ng.neurology.org/content/4/6/e300.full.html }\end{array} \\ \text { References } & \begin{array}{l}\text { This article cites } 1 \text { articles, } 1 \text { of which you can access for } \\ \text { http://ng.neurology.org/content/4/6/e300.full.html\#\#ref-lis- }\end{array} \\ \text { Permissions \& Licensing } & \begin{array}{l}\text { Information about reproducing this article in parts (figure } \\ \text { its entirety can be found online at: } \\ \text { http://ng.neurology.org/misc/about.xhtml\#permissions }\end{array} \\ \text { Reprints } & \begin{array}{l}\text { Information about ordering reprints can be found online: } \\ \text { http://ng.neurology.org/misc/addir.xhtml\#reprintsus }\end{array}\end{array}$

Neurol Genet is an official journal of the American Academy of Neurology. Published since April 2015, it is an open-access, online-only, continuous publication journal. Copyright (C) 2018 American Academy of Neurology. All rights reserved. Online ISSN: 2376-7839.

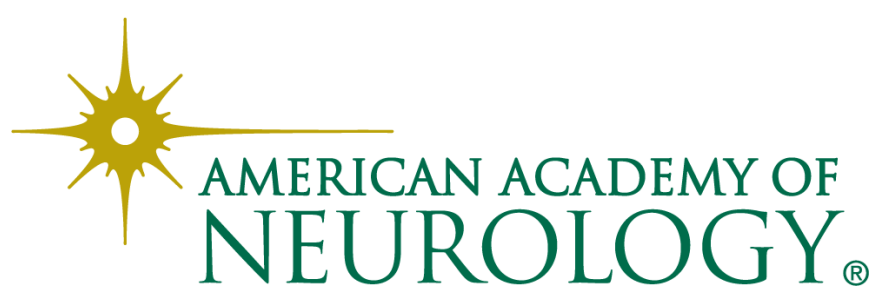

